Preprints of the

Max Planck Institute for

Research on Collective Goods

Bonn 2015/6

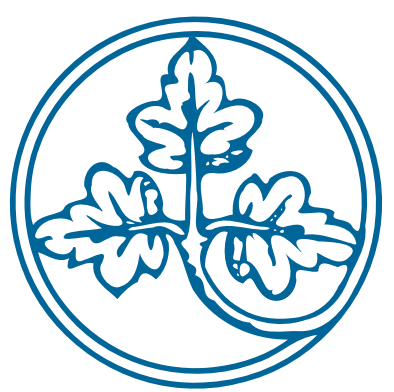

Communication and Trust in

Principal-Team Relationships:

Experimental Evidence

Marco Kleine

Sebastian Kube

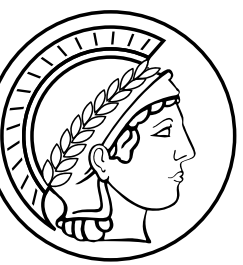




\title{
Communication and Trust in Principal-Team Relationships: Experimental Evidence
}

\author{
Marco Kleine / Sebastian Kube
}

March 2015 


\title{
Communication and Trust in Principal-Team Relationships: Experimental Evidence*
}

\author{
Marco Kleine $e^{\dagger} \&$ Sebastian Kube ${ }^{\ddagger}$
}

\begin{abstract}
We study how upward communication - from workers to managers - about individual efforts affects the effectiveness of gift exchange as a contract-enforcement device for work teams. Our findings suggest that the use of such self-assessments can be detrimental to workers' performance. In the controlled environment of a laboratory gift-exchange experiment, our workers regularly overstate their own contribution to the joint team output. Misreporting seems to spread distrust within the team of workers, as well as between managers and workers. This manifests itself in managers being less generous with workers' payments, and in workers being more sensitive to the perceived kindness of their relative wage payments. By varying the source and degree of information about individual efforts between treatments, we see that precise knowledge about workers' actual contributions to the team output is beneficial for the success of gift-exchange relationships. Yet, workers' self-assessments can be a problematic tool to gather this information.
\end{abstract}

JEL Classification: C92, J33, M52

Keywords: communication, gift exchange, incomplete contracts, reciprocity, performance appraisal, self-assessment, work team, laboratory experiment

\footnotetext{
*We thank Christoph Engel, Armin Falk, Minou Ghaffari-Tabrizi, Ammar Mahran, Isabel Marcin, and Matthias Wibral for helpful comments and support. The paper also benefited from comments and suggestions by conference participants at the IMEBE in Castellón and at the ESA conferences in Luxembourg and New York, as well as by seminar participants at the Workshop on Co-Determination and Employee Participation in Trier, at the Incentive and Behavior Change Workshop in Amsterdam, at the Spring School in Behavioral and Experimental Economics in San Diego, at the Max Planck Institute for Research on Collective Goods in Bonn, and at the Max Planck Institute for Innovation and Competition in Munich.
}

${ }^{\dagger}$ Max Planck Institute for Innovation and Competition, Munich.

${ }^{\ddagger}$ University of Bonn, and Max Planck Institute for Research on Collective Goods, Bonn, and IZA. 


\section{Introduction}

The organization of work in teams is widespread. A central question not only for work teams is how to incentivize workers to exert effort, in particular given the inherent problem of freeriding in teams (Holmström 1982). Theoretical solutions to the problem usually build on the use of complete incentive contracts, either conditioning on each team member's individual output (e.g., Prendergast 1999; Lazear 2000), or on joint team output (e.g., Winter 2004; Goerg et al. 2010). Yet, actual contracts are frequently incomplete and leave workers with discretion over their work effort - especially when important effort dimensions are not contractible, or only imperfectly observable by the principal. The gaps left by contractual incompleteness might be successfully filled by mechanisms aiming at workers' reciprocal motivation (e.g., Fehr et al. 2009). In this paper, we explore a very prominent mechanism, gift exchange, when the principal faces a multi-agent setup (Abeler et al. 2010; Gächter et al. 2012). Our focus is on the role of information and (cheap-talk) communication in this environment and its impact on the effectiveness of gift exchange as a contract enforcement device for work teams.

Since the seminal work by Akerlof (1982) and the early lab experiments by Fehr et al. (1993, 1997), there has been an ever-growing interest in gift exchange in employment relationships. What has been identified as a central factor for successful gift exchange is the perceived fairness and kindness of the principals "gift" (e.g., Falk 2007; Kosfeld and Neckermann 2011; Kube et al. 2012). In bilateral employer-employee relationships, a common interpretation of the firm's kindness is the absolute size of the wage payment (yet, see Gneezy and List 2006; Kube et al. 2013; Cohn et al. 2013/forthcoming). For work teams, however, the perceived fairness of wage payments not only depends on the absolute size of the wages. Additionally, social comparisons play an important role. When judging the appropriateness of their own wage, workers relate it to their peers' wages (Card et al. 2012). If they feel treated less favorably, work motivation and efforts are reduced (Clark et al. 2010, Gächter and Thöni 2010, Cohn et al. 2012/forthcoming). This does not only apply to the case of unequal wage payments. Dissatisfaction can also arise under wage equality, because workers often take effort differences into account as well; i.e., they consider relative payoffs, including effort costs, rather than wage differences per se (Mowday 1991). This implies that, in multi-agent environments, even equal wage payments can be inequitable and thus detrimental for gift 
exchange (Abeler et al. 2010). In fact, whenever workers in a team differ in their performance and the principal observes only the joint team output, the power of gift exchange is likely to be limited.

In this paper, we test whether communication about individual effort levels is able to alleviate this common problem. The focus is on upward communication that flows from the agents to the principal. Agents are asked to report their own effort - which they usually should know to the principal. Such self-assessments by the employees are frequently used in firms, typically as part of the evaluation process in performance appraisals. They might provide a valuable source of information for the successful establishment of gift-exchange relationships in work teams. If the reported effort levels are sufficiently truthful and the principal sets individual wages accordingly, such that hard-working agents earn more than lazy agents, gift exchange might prevail. ${ }^{1}$ On the other hand, self-assessment in this setup is still only cheaptalk communication. If workers expect the principal to tailor wages to the reported effort levels, there exist monetary incentives to misreport and exaggerate their own effort. In that case, the principal would be left with the same amount of information as if he had only observed the joint team output; making it again difficult to establish effective gift-exchange relations with the work team. Maybe even worse, the potential for misreporting might actually spread distrust within the team, which in turn could be harmful to successful gift exchange.

Whether workers report their effort levels truthfully or exaggerate them - and thus if this specific form of communication really helps to improve on the power of gift exchange for work teams or even harms it - is ultimately an empirical question. Ideally, it would be tested in identical work environments that only differ in the availability of self-assessments. Furthermore, individual effort levels would need to be perfectly observable by the researchers, but not by the firm (otherwise, reporting of effort levels would not be necessary). While these requirements are difficult to be met in the field, the controlled environment of laboratory experiments offers the necessary degree of control for establishing causal

\footnotetext{
${ }^{1}$ Recent empirical evidence suggests that many people suffer psychological costs from lying (e.g., Gneezy 2005, Fischbacher and Föllmi-Heusi 2013). In our context, this implies that at least some workers should refrain from strategically misreporting their private information and instead report their true effort levels - in particular if the principal's wage payments lead to payoff improvements (see also the related arguments in Charness and Dufwenberg 2011 for the case of workers revealing hidden information about their personal skills).
} 
relationships between communication and gift-exchange behavior. We therefore conducted lab experiments using a gift-exchange game in which a principal interacts repeatedly with a team of two agents. Agents provide costly effort, which is of value to the principal. The principal receives information about the agents' effort levels and then decides on their wage payments. The amount and source of information is varied between treatments, so that, depending on the treatment, individual effort is not observable and/or not contractible. In treatment TEAM, the principal can only observe the joint team output, given by the sum of individual efforts. This treatment serves as an estimate for the basic effectiveness of gift exchange with work teams if the principal has no precise information about the individual effort levels. In our second treatment, MESSAGE, communication is introduced. Both agents send a message about their individual effort level to the principal. These messages, which might be truthful or purely cheap talk, are then transmitted to the principal (in addition to the joint team output, which the principal also observes in TEAM). By comparing actual efforts and messages, we can check how agents use the communication and to what extent principals should rely on these reports. Following this, we can see to what degree the use of upward communication helps to improve the effectiveness of gift exchange as a contract enforcement device in multi-agent environments with imperfect information. To reassure that gift exchange can potentially work if precise information is available to the principal, treatment INDIVIDUAL is conducted. Here, the principal has complete information about the team output and about each agent's individual output. The treatment serves as our benchmark for the maximum efficiency gains that are to be expected from gift exchange with work teams.

In our data, we find a positive correlation between effort and wages in all three treatment conditions. On average, high efforts are remunerated with higher wages than low efforts, suggesting the presence of basic gift exchange on a bilateral basis (that is, without taking social comparisons into account). However, gift exchange seems to develop its full potential only if relative payments constantly reflect the differences in effort provision within a work team, too. In treatment INDIVIDUAL, on average about $84 \%$ of the maximum efficiency gains are realized. This ratio drops to $61 \%$ in treatment TEAM, where principals can only observe the joint team output. Strikingly, efficiency gains are lowest in treatment MESSAGE (44\%). This is particularly notable for two reasons. First, the amount of available information is weakly larger in MESSAGE than in TEAM, since agents' messages provide reliable information for the principal $(63 \%$ of all messages are truthful, and many of the remaining reports only 
depart slightly from the true effort choice). Second, principals seem to notice this and condition their wage payments on agents' messages, so that relative wage payments are frequently in line with the actual differences in effort levels.

We interpret the significantly lower performance in MESSAGE as an indication that this specific form of communication constitutes a potential source of distrust, which in turn is detrimental for establishing successful gift-exchange relationships. First, the principal's trust might be lowered when he detects that workers misreport their efforts, inducing him to be less kind to the workers. Indeed, we find that principals pay different wages when they observe that the sum of reported efforts do not match the joint team output. Second, workers might expect their peers to overstate their efforts. This might cause them to be more sensitive to relative wage payments, and to be more likely to perceive the size of wage differences as unjustified and unkind. In fact, we estimate agents' negative effort reactions following unfair wage payments to be strongest in treatment MESSAGE.

These observations are particularly interesting in light of the large management literature on performance appraisals (for a recent contribution, see Berger et al. 2013 and the references therein). This literature stresses the need for subjective performance evaluations in firms, but also acknowledges its shortcomings (in particular biases in rating behavior) and potential detrimental effects on agents' work motivation. The additional use of self-assessments by the workers is frequently meant to mitigate these problems. It is suggested that agents' participation in the appraisal process is key to trust-building and work motivation (e.g., Mayer and Davis 1999, Levy and Williams 2004). Our results complement this view. They demonstrate that self-assessments can, at least to a certain extent, be informative for the principal in environments where workers have sufficiently precise knowledge about their own efforts. At the same time, they indicate that, in work relationships that are built on notions of gift exchange, the employment of self-assessments carries the risk of inducing distrust and lowering work morale. Given that self-assessments serve a function beyond being a purely evaluative tool (e.g., Campbell and Lee 1988), their effective use might thus require foregoing the opportunity to tie payments to the subjective performance evaluations (see also Prendergast and Topel 1993, who argue more generally that "suppressing information on relative performance may enhance overall incentives and output” (p. 356)). 
Our paper also informs the growing literature in economics on cheap-talk communication (see Crawford 1998 for a general survey). Studies in this field usually focus on the beneficial effects of communication opportunities (e.g., Balliet 2010). With respect to organizations, however, the evidence is less conclusive. For instance, public messages sent by the principal can help to mitigate coordination failures among agents (Brandts and Cooper 2007). Similarly, Mohnen and Pokorny (2006) and Rosaz (2012) show that the principal's potentially untruthful feedback about an agent's ability or performance can also be beneficial to the firm - although this comes at the cost of reducing the agent's payoff due to an increase in effort (which can subsequently be harmful to the firm, see Sebald and Walzl 2014). Moreover, the same kind of cheap-talk feedback from manager to workers, which increases performance in the single-agent case, can backfire and hamper effort provision in a dynamic promotion tournament between agents (Ederer and Fehr 2007). Our study underlines the potential drawbacks that might arise from communication, but now it is communication from agents to principals. To the best of our knowledge, Cooper and Lightle (2013) is the only other study where employees can send cheap-talk messages to the employer, but it is not concerned with information transmission in team settings. While Cooper and Lightle also explore the effect of communication on gift exchange, their focus is different to ours and their conclusion is rather positive. In their bilateral setup with perfect information, the principal makes an unconditional wage payment and the agent then exerts costly effort. If agents are allowed to send a freeform text message of any content to the principal, they mainly use it to advice the principal to set high wages. Principals follow the advice, which strengthens the gift-exchange relationship and induces agents to exert effort. ${ }^{2}$ For this to happen, however, our results suggest that it might be crucial to have precise information on agents' actual effort levels - otherwise, potentially dishonest messages might easily spread distrust and weaken the effectiveness of gift exchange as a contract enforcement device.

Finally, the present study ties in with a growing empirical literature in behavioral personnel economics, which documents the influence of organizational details and incentive systems on work behavior (see Charness and Kuhn 2011 for a recent review). This study complements the literature by underlining that the structure of communication layers in organizations can strongly impact workers' performance - even in cases where, according to economic models

\footnotetext{
${ }^{2}$ See also Corgnet and Hernán-González (2013), who use a related task for studying situations where principals do not follow agents' advice.
} 
with standard preference assumptions, one would not expect communication to make a difference. As such, our study is closely related to the widespread debate on the optimal degree of transparency in organizations, in particular with respect to pay secrecy (Charness and Kuhn 2007, Cabrales and Charness 2011, Greiner et al. 2011, Nosenzo 2013, Lount and Wilk 2014, Ockenfels et al. forthcoming). Furthermore, our results add an important piece to the picture of the effectiveness of gift exchange in complex, multi-agent employment relations (Maximiano et al. 2007, Bartling and von Siemens 2011, Gächter et al. 2012, 2013, Gose and Sadrieh 2014). While it seems to be generally possible to establish successful gift-exchange relationships, the necessary prerequisites of perceived fairness, kindness, and trust might turn out as fragile concepts that are apparently susceptible to small and seemingly irrelevant changes in the work environment. This implies that gift exchange is not always a panacea, and that different environments might require (a combination of) different approaches, like tournaments (e.g., Bandiera et al. 2013), incentive pay (e.g., Burks et al. 2009), or work goals (e.g., Goerg and Kube 2012).

\section{Experimental Design and Procedures}

The experimental design is based on a stylized model of an employment relationship with contractual incompleteness, namely a multi-agent, reversed gift-exchange game (see also Abeler et al. 2010). The treatments, which will be described in detail below, are chosen to clearly isolate the impact of upward communication on the effectiveness of gift exchange as a contract enforcement device.

Basic Structure One principal (the employer) interacts with two agents (the employees) repeatedly over a finite number of periods. Each period consists of two decision stages, i) an effort stage followed by ii) a wage-setting stage.

At the first stage, both agents decide independently and simultaneously on the provision of their individual effort $e_{i} \in\left[e_{\min } ; e_{\max }\right]=[1 ; 10]$. Every unit of effort produces a payoff of 10 for the principal. Effort is costly for the agent (except for $e_{\min }$ ), with the associated cost function $C\left(e_{i}\right)$ being increasing and convex in effort (cp. Table 1). 


\begin{tabular}{|c|l|l|l|l|l|l|l|l|l|l|}
\hline $\begin{array}{c}\text { Individual } \\
\text { Effort Level } e_{i}\end{array}$ & 1 & 2 & 3 & 4 & 5 & 6 & 7 & 8 & 9 & 10 \\
\hline $\begin{array}{c}\text { Cost of Individual } \\
\text { Effort } C\left(e_{i}\right)\end{array}$ & 0 & 1 & 2 & 4 & 6 & 8 & 10 & 13 & 16 & 20 \\
\hline
\end{tabular}

Table 1: Cost of individual effort.

At the second stage, the principal is informed about the joint team effort, given as the sum of individual efforts. Depending on the treatment, this is either his only information about agents' efforts, or he additionally receives information about agents' (self-reported or actual) individual effort levels. He then decides on the individual wage payments $w_{i} \in[0 ; 100]$ for the agents, i.e., he can pay equal wages $w_{1}=w_{2}$, but he can also discriminate between agents and set $w_{1} \neq w_{2}$.

At the end of the game, in addition to information about individual and team efforts, agents learn their own and their co-agent's wage payments and corresponding payoffs, as well as the principal's payoff. Depending on the treatment, the principal is shown his own payoff only, or he additionally receives information on the payoff of the agents (either their actual payoff, or their payoff conditional on self-reported effort being honest). The payoffs are given by:

Principal's payoff: $\quad \pi_{P}=10\left(e_{1}+e_{2}\right)-w_{1}-w_{2}$

Agent $i$ 's payoff: $\quad \pi_{i}=w_{i}-C\left(e_{i}\right)$

Treatments To isolate clearly the influence of communication, all treatments share the above game structure. However, the amount of information available to the principals is varied between treatments:

Treatment TEAM: At the wage-setting stage, the principal observes only the joint team effort. He receives no information about the agents' individual effort levels. ${ }^{3}$

\footnotetext{
${ }^{3}$ Due to the deterministic production function, however, the principal can directly infer from the extreme team efforts of 2 (20) that both agents exerted an individual effort of 1 (10). Note that the same would hold true had we introduced a noise term to the production function as long as principals know the extremes of individual efforts and noise. The only way to avoid this is by not telling principals about the range of feasible efforts, but this in itself has been shown to pose problems for gift exchange to prevail (Hennig-Schmidt et al. 2010). By refraining from introducing a noise term or incomplete information about feasible effort ranges, we attempt to avoid confounds between the pure effect of reporting on gift exchange and additional effects of white noise.
} 
Treatment MESSAGE: Before the beginning of the wage-setting stage, both agents can send a (cheap-talk) message about their own effort level to the principal. These messages are chosen simultaneously and independently, knowing actual individual contributions, as well as the actual team effort. The reported individual effort need not coincide with the actual effort, but has to be feasible. ${ }^{4}$ At no point in time are the agents informed about the content of their coagent's message, but they know the actual effort levels.

Principals at stage two are again informed about the joint team effort, but additionally receive agents' messages about the reported individual efforts.

Treatment INDIVIDUAL: At the wage-setting stage, the principal observes the joint team effort and each agent's actual effort.

Procedure We used a between-subject design, with subjects being randomly assigned to treatment conditions. The general procedure was the same for all treatments. Upon arriving at the lab, subjects were seated in private cubicles. Instructions were distributed and read out aloud to create common knowledge about the game structure and payoffs. ${ }^{5}$ In order to ensure that all participants had understood the basic game structure, comprehension questions could be posed in private, and participants had to answer control questions. The game only started after everyone had answered the control questions correctly.

At the beginning of the game, participants were randomly assigned to the roles of agents or principals and randomly matched in groups of three (one principal and two agents). Roles and groups remained constant over all twelve periods. ${ }^{6}$ At the end of the experiment, participants

\footnotetext{
${ }^{4}$ The reported individual effort has to be chosen in a feasible way, i.e., it cannot be larger than the team effort minus the minimal individual effort of the co-agent. Thus, as discussed in the previous footnote, extreme effort combinations (both agents choosing an actual effort of 1, or both choosing 10) rule out misreporting.

${ }^{5}$ The experiment was conducted in a labor-market framing, but loaded words were avoided (that is, we did not use words like "shirking", "team", "lie", etc.). The original instructions are in German.

${ }^{6}$ With the partner design and the repeated game structure, we focused on a natural employment environment, in which principals and agents interact repeatedly and teams work together over some periods. In such an environment, agents within the teams typically know the ability of their co-agents (in this case, all agents have the same ability and are aware of it). Furthermore they get to know the other team members' behavior as well as their principal's behavior over time and may adapt their own behavior accordingly. Similarly, the principals may learn gradually about the team behavior and - depending on the treatment - about (some aspects of) the individual agents' behavior.
} 
conducted a test to assess their general risk attitude (Dohmen et al. 2011) and answered a general socio-economic questionnaire. Subjects were then paid in private and left the lab.

All experiments were run at the BonnEconLab at the University of Bonn, Germany. The experimental software was z-Tree (Fischbacher 2007) and participants were randomly recruited from a pool of approximately 7000 subjects using the recruitment software ORSEE (Greiner 2004). ${ }^{7}$ Subjects were only allowed to participate once. For each of the treatments, we conducted two sessions with 24 participants each (in total 144 participants). Due to the partner design, a matched group of one principal and two agents constituted one independent observation, leaving us at the group level with 16 independent observations per treatment.

Each session lasted for about 110 minutes. Payoffs were converted into Euros at an exchange rate of 0.02 EUR per point. On average, participants earned 16.34 EUR (including an initial show-up fee of 200 points, the earnings from all periods of the experiment, and potential earnings from the risk-attitude assessment).

\section{Behavioral Predictions}

Under the standard assumptions of rational and self-centered money-maximizing players, subgame-perfect equilibrium predictions do not depend on our treatment conditions. In the one-shot game, principals will choose the lowest wage payment $w_{i}=0$ for both agents, because any strictly positive wage payment would reduce the principals' monetary payoff. Anticipating this, agents will exert the minimum individual effort $e_{i}=e_{\min }=1$, since costs of effort provision are increasing in $e$ and agents' monetary payoff thus decreases in $e$. Playing the game repeatedly over a finite number of periods ( $t=12$ in our case), the game unravels from the last period. Thus, the unique subgame-perfect equilibrium is that the principal pays zero wages and each agent chooses the minimum individual effort in all periods. The equilibrium prediction for rational and self-centered money-maximizing players is not affected by the treatment differences, i.e., it holds regardless of whether the principal

\footnotetext{
${ }^{7}$ Apart from previous experience with gift-exchange experiments, we defined no exclusion criterion. In our sample, the average age is 22.96 . We have $67 \%$ female participants. $91 \%$ are undergraduate students from various fields, the two largest groups being Economics (21\%) and Law students (20\%).
} 
only knows the joint team effort (TEAM), receives non-verifiable "cheap talk" messages about agents' individual efforts (MESSAGE), or observes each agent's actual effort (INDIVIDUAL).

Note that, in equilibrium, large efficiency gains are forgone. Given the parameters that we implemented, the marginal product of effort provision exceeds its marginal cost for all levels of effort. Thus, if we define efficiency simply as the sum of monetary payoffs, efficiency is highest if both agents exert the maximum amount of effort $\left(e_{i}=e_{j}=10\right)$. However, theoretical models that derive the corresponding prediction of both agents exerting full effort would need to alter assumptions about rationality or adopt a richer set of preferences that are not exclusively built on strictly monotone transformations of the individual's monetary payoffs.

These alternative models would also introduce the possibility of our treatment manipulations altering the predictions. In particular, the additional information in treatments MESSAGE and INDIVIDUAL can make a difference for players' behavior if they are not purely self-centered money maximizers, but instead act reciprocally (which is something that is frequently observed in gift-exchange experiments). To see why, consider that the perceived fairness of the players' actions is a key element in successful gift-exchange relationships. In multi-agent environments, this implies that agents' payoffs need to follow a general equity principle (Abeler et al. 2010, Gächter et al. 2012). The equity principle prescribes that, within a work team, equal efforts should be rewarded with equal payments, and agents with high efforts should earn more than agents with low efforts. ${ }^{8}$ Therefore, even equal wage payments can be inequitable whenever workers differ in their performance.

The latter situation easily arises in treatment TEAM, because the principal observes only the team output, but lacks information about individual efforts. Hence, he might frequently violate the equity principle, which disturbs the gift-exchange relationship and has detrimental effects on agents' work motivation. By contrast, in treatment INDIVIDUAL the principal observes team output and individual outputs, allowing him to tailor workers' pay to individual efforts. By following the equity principle, workers' fairness considerations are fulfilled and

\footnotetext{
${ }^{8}$ Formally, $\pi_{i}=\pi_{j}$ iff $e_{i}=e_{j}$, and $\pi_{i}>\pi_{j}$ iff $e_{i}>e_{j}$.
} 
gift exchange can flourish. The upward communication in treatment MESSAGE could also potentially enable principals to set wages that are in line with the equity principle. A necessary prerequisite in MESSAGE, however, is that agents' reported effort levels are sufficiently truthful. Otherwise, tailoring payments to pure cheap-talk messages would result in violations of the equity principle, hampering the establishment of successful gift-exchange relationships.

One might hypothesize that self-assessments are sufficiently sincere for at least three reasons. First, recent research on honesty and deception in other domains demonstrates that a substantial fraction of agents reveal a preference for truth-telling, because, e.g., agents incur psychological costs of lying, are guilt-averse or have social-image concerns (Gneezy 2005, Charness and Dufwenberg 2006, Sanchez-Pages and Vorsatz 2007, Fischbacher and FöllmiHeusi 2013). Second, if agents suffer strongly from violations of the equity principle, insincere reports are weakly dominated by the strategy to report the actual effort truthfully; provided that the principal's wage-setting takes the self-assessments into account such that payments adhere to the equity principle. Third, if truthful reports and subsequent adherence to the equity principle induces successful gift-exchange relationships, efficiency is increased and, consequently, agents' monetary payoffs potentially increase as well (given that the principal allocates corresponding shares of the efficiency gains to the agents). On the other hand, truthful reporting also constitutes a cooperation problem for the agents. If, ceteris paribus, an agent's payoff increases in his reported effort level, agents might be tempted to overstate their own effort for monetary reasons. However, principals in our setting can compare the sum of the reported individual efforts with the actual team output; misreporting in the team would be detected and principal's wage setting could potentially react to it.

Summing up, no treatment effects are to be expected under standard predictions. In the presence of reciprocal players, previous experiments suggest that efficiency should be higher in INDIVIDUAL than in TEAM. The upward communication in treatment Message, which is novel and the focus of our paper, yields the potential to increase efficiency in comparison to treatment TEAM. This, however, requires messages to be sufficiently truthful. Otherwise, the principal again only knows the joint team output and would be back in the situation of treatment TEAM. 


\section{Results}

In the following, we first present results on treatment differences in effort provision and efficiency. As will be seen, efficiency is lowest in treatment MESSAGE. To better understand this finding, we subsequently study reporting behavior by looking at the role of selfassessments as a potential source of i) additional information as well as ii) distrust among players. Therefore, we compare effort-wage relationships across treatments to show how gift exchange is affected by the amount and the source of information about individual efforts. Moreover, we explore principals' generosity in treatment MESSAGE in more detail, focusing especially on differences between periods with and without misreporting. This also allows us to check whether principals' wage payment patterns provide incentives for the agents to misreport their effort.

\section{Effort Choices, Efficiency, and Profit}

The agents' willingness to exert effort is lower if the principal is only informed about total team output rather than about actual individual efforts. In treatment TEAM, agents exert an average effort of 6.1. In treatment INDIVIDUAL, the average effort of 8.4 is significantly higher (Wilcoxon rank sum test: $p=.004) .{ }^{9}$ Can non-binding, non-verifiable messages on individual efforts reinstall agents' work morale and enhance efficiency? A look at effort provision in treatment MESSAGE shows that it cannot: the average effort of 4.4 is significantly lower than in INDividuAL and even substantially lower than in TeAm (Individual vs. Message: $p<.0001$; TeAm vs. MeSSAGE: $p=.046$, both Wilcoxon rank sum tests).

The histogram of individual effort choices on the left-hand side of Figure 1 illustrates the striking differences in effort provision across treatments. In TEAM, the maximal effort of 10 is the modal effort choice (23.4\% of all observations). In INDIVIDUAL, agents even choose maximal effort in the majority of all cases $(59.4 \%)$. Contrarily, high effort is rarely chosen in treatment MESSAGE (maximal effort in only $7.3 \%$ of all cases). The modal effort choice in MESSAGE is the minimal effort of $1(28.4 \%)$.

\footnotetext{
${ }^{9}$ Unless stated otherwise, all non-parametric tests are based on averages per matching group as independent observations, and reported p-values are always two-sided.
} 

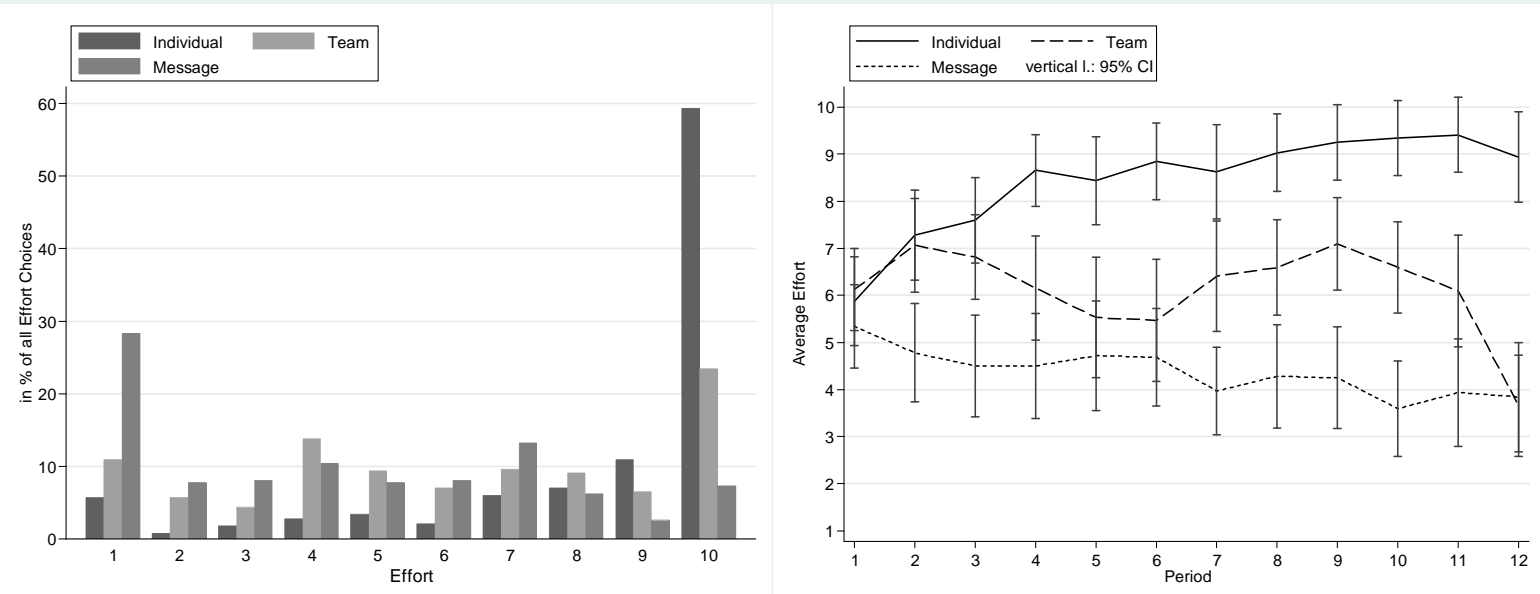

Figure 1: Left: Frequency of individual effort choices. Right: Average individual effort per period - the individual effort is aggregated per period over all matching groups.

The pronounced differences in effort across treatments are driven by different developments of effort provision over time (compare the right-hand side of Figure 1). In all treatments, agents start with similar effort levels. Average effort in the first period is 6.1 in treatment TEAm, 5.9 in Individual, and 5.3 in Message, the differences being not statistically significant (Wilcoxon rank sum test of first-period effort; TEAM vs. INDIVIDUAL: $p=.7189$, TeAm vs. Message: $p=.3065$, Message vs. Individual: $p=.5318)$. In Individual, agents rapidly increase their efforts and stick to the high effort levels until the last period (Spearman rank correlation coefficient between period and average effort per matching group per period: $\rho=.5657, p<.0001)$. By contrast, efforts in treatments MESSAGE decrease almost monotonically over time ( $\rho=-.1687, p=.0193)$. In TEAM, there is also a weak negative time trend, albeit mostly due to a pronounced endgame effect $(\rho=-.1272, p=.0786$; resp. $\rho=.0031, p=.9670$ if final period is excluded).

\begin{tabular}{|c|c|c|c|}
\cline { 2 - 4 } \multicolumn{1}{c|}{} & INDIVIDUAL & TEAM & MESSAGE \\
\hline Principals & 71.1 & 56.2 & 47.1 \\
\hline Agents & 33.2 & 23.5 & 14.4 \\
\hline
\end{tabular}

Table 2: Average profit per period. 
Given the specific parameters for our production and cost functions, effort differences directly translate into efficiency differences. Table 2 summarizes that both agents and principals are best off in treatment INDIVIDUAL, followed by TEAM and the least efficient treatment Message. ${ }^{10}$

Result 1: Compared to a situation where only the joint team output is observed, the additional availability of self-assessments does not improve agents' performance. On the contrary, effort provision in MESSAGE is even worse than in the absence of information about individual efforts (TEAM). Agents provide high efforts only in INDIVIDUAL, where principals can observe the actual effort levels of both agents.

\section{Self-assessments}

Why is the performance in MESSAGE significantly worse than in the other two treatments? To shed light on this, we first look at agents' reporting behavior.

We find that the amount of available information in MESSAGE is weakly larger than in TEAM, but lower than in INDIVIDUAL. Although the principal cannot verify the self-assessments, 63\% of all reports coincide with the actual effort level. Still, misreporting is a common phenomenon since $37 \%$ of all reports are untruthful. Moreover, note that over-reporting as the most likely source of misreporting is not possible for all combinations of effort choices, as the reporting space is restricted to meaningful reports. ${ }^{11}$ Considering only those cases in which over-reporting is possible (247 out of 384 instances), overall we find reports to be insincere in the majority of these instances (57.5\%). At the individual level, most agents (64.5\%) misreport at least once when they face a situation that leaves room for over-reporting; $25.8 \%$ always misreport; and only $9.7 \%$ of the agents never misreport. Within a work team, the agent

\footnotetext{
${ }^{10}$ Wilcoxon rank sum test comparing average profit per period - Individual vs. team: $\mathrm{p}=.026$ (principals), $\mathrm{p}=.032$ (agents); Individual vs. Message: $\mathrm{p}=.008$ (principals), $\mathrm{p}=.002$ (agents); Team vs. Message: $\mathrm{p}=.132$ (principals), $\mathrm{p}=.055$ (agents).

${ }^{11}$ Agents are not allowed to report individual efforts above the joint team output, and they cannot report an individual effort above the maximum individual effort of ten. Moreover, agents cannot overstate their effort if they chose the maximum effort of 10, or if the co-agent chose the minimum effort of 1 (but in both cases, they can understate the effort if they want to). Consequently, if both agents choose $e=10$, or if both choose $e=1$, reporting is truthful per design.
} 
with the lower effort is more likely to misreport than his hard-working co-agent (Pearson's chi-squared test, $p<.0001) .^{12}$

Apart from the absolute number of dishonest reports, it is of interest by how much and in which direction the insincere reports depart from the truth. When agents lie, they almost exclusively overstate their own effort (98\% of all lies are over-reports). However, as can be seen in Figure 2, misreporting to the maximum extent possible is rather rare. On average, agents over-report only $31 \%$ of the maximum possible exaggeration (excluding those instances where over-reporting is not possible). This might partly be due to people trying to maintain a positive self-image with regard to honesty and fairness considerations towards their coworker, but also the strategic aspect of establishing credibility and reputation towards the principal might play a role.

Result 2: In general, a substantial fraction of reports coincide with the actual effort. Still, when misreporting is possible, the majority of self-assessments are dishonest. Insincere reports almost exclusively take the form of over-reporting, mostly depart only slightly from the actual effort level, and are more likely to be given by the low-effort agent in the work team.

Given that agents frequently misreport, and given that misreporting is almost always in the same direction (overstatements), principals occasionally learn that reports are insincere. ${ }^{13}$ For example, if a principal observes a team effort of 12 and the sum of reported effort is 14 , he can infer that at least one of the agents over-reported the individual effort. On average, a principal faces misreporting in $56.25 \%$ of all periods. Moreover, in another $24.5 \%$ of all periods, reporting is superfluous, as both agents in the team had chosen either the maximum or the minimum effort. Hence, a principal receives reliable additional information from the agents in only $19.25 \%$ of all periods.

\footnotetext{
${ }^{12}$ When agents exert lower effort than the co-agent they misreport in $77 \%$ of all cases in which over-reporting is possible. Harder-working agents or those who exert the same effort as their co-agents only misreport in $37 \%$ of all possible cases.

13 It has to be qualified that principals can only "observe" misreporting if they correctly conjecture that underreporting is very unlikely to occur. Furthermore, note that although principals can infer misreporting at the team level, they are unable to attribute misreporting to a specific agent.
} 


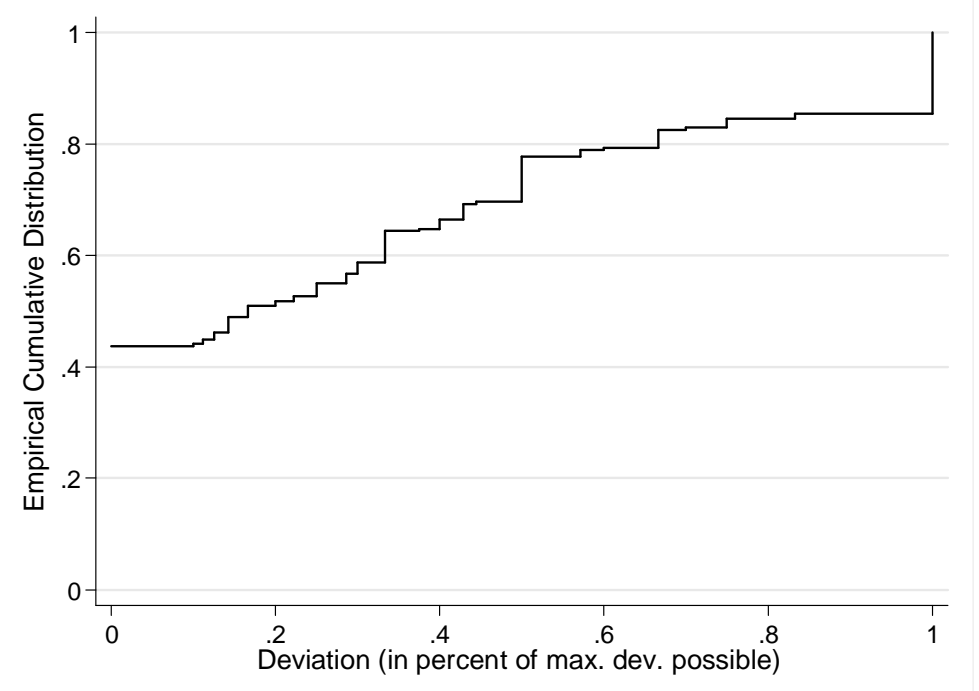

Figure 2: Empirical Cumulative Distribution - deviations of reported individual effort from actual individual effort in percent of the maximum over-reporting possible. Only those reports are included for which overstating was possible. For the ease of interpretation, understatements are excluded (0.8\% of all observations, resp. $2 \%$ of all lies).

\section{Wage-Setting and Reciprocity}

Although misreporting is common, its impact on the gift-exchange relationship need not be negative per se. Therefore, we now check if and how the principals' wage-setting behavior is affected by the presence of self-assessments. Moreover, we will test if the common form of "over-reporting while under-performing", which was observed in the previous section, can (c.p.) be part of a profitable strategy for an agent.

Figure 3 shows average wages for a given individual effort. As indicated by the strong upward slope in all three treatments, a higher effort is, on average, reciprocated with higher wages. ${ }^{14}$ Hence, even in MEssage and in TEAM, we see the typical gift-exchange pattern that has been reported before for many bilateral gift-exchange settings.

Result 3: In all three treatments, higher efforts are on average remunerated with higher wages.

\footnotetext{
${ }^{14}$ The observation of a positive effort-wage relationship at the individual level also holds at the team level for the team effort - team compensation relationship $\left[\left(e_{i}+e_{j}\right)\right.$ vs. $\left.\left(w_{i}+w_{j}\right)\right]$.
} 


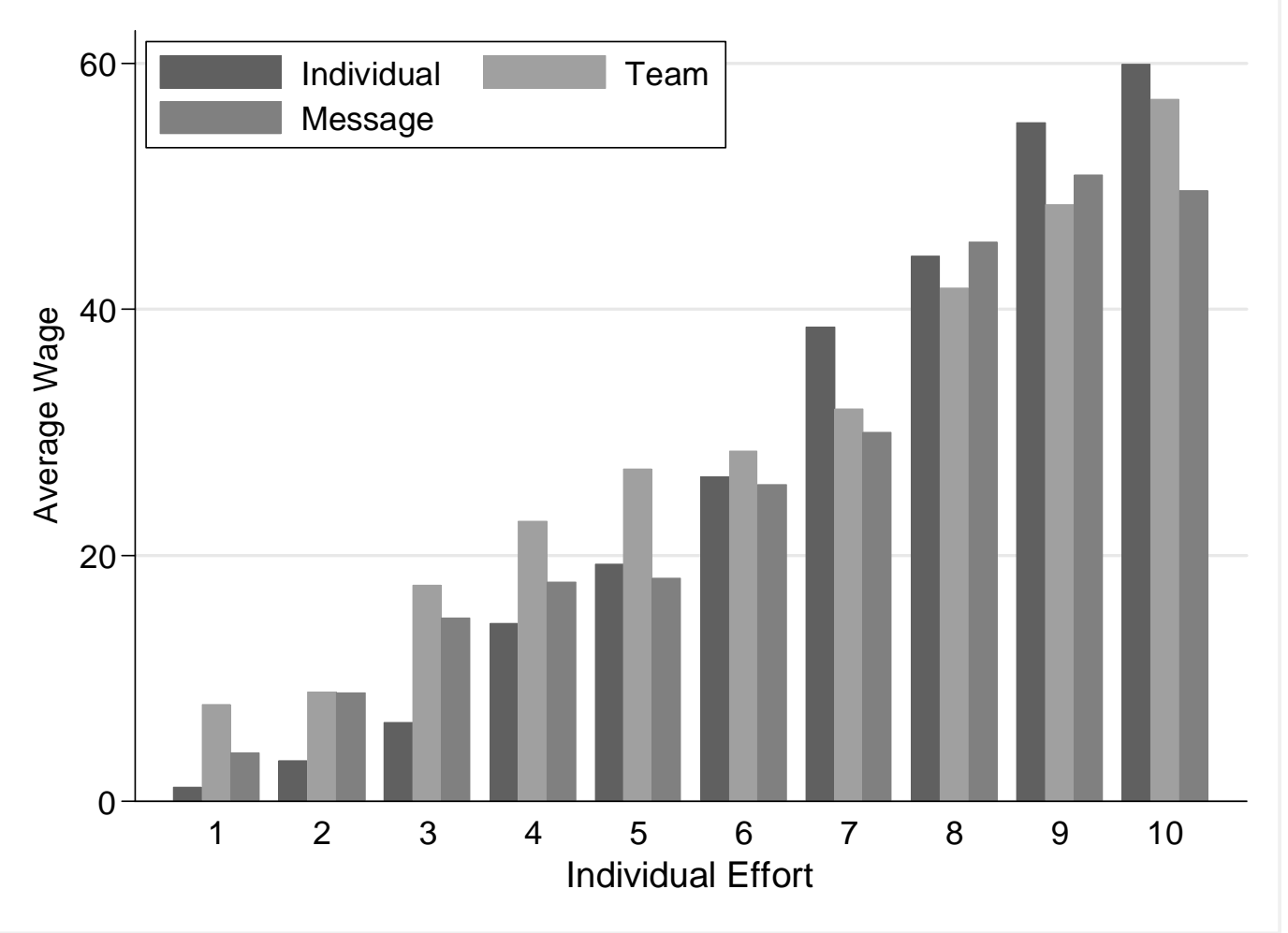

Figure 3: Average individual wage for a given individual effort (actual efforts).

After having shown that the general gift-exchange pattern is similar in all three treatments, a closer analysis of the determinants of wage-setting reveals that differences in the principals' information about individual effort lead to significant differences in the way principals reward the agents' effort. In order to investigate wage-setting behavior in greater detail, we run fixed effects regression analyses and test the impact of individual effort and team effort separately for each treatment (compare Models 1 to 3 in Table 3).

As expected, due to the lack of information about individual efforts in treatment TEAM, wagesetting is not significantly influenced by agents' individual effort - the coefficient for individual effort $e_{i, t}$ in Model 1 is insignificant and close to zero. Instead, principals condition their wages on the only information available: the coefficient for the team effort $e_{i, t}+e_{j, t}$ is substantial and significant. 


\begin{tabular}{|c|c|c|c|c|c|c|}
\hline $\begin{array}{c}\text { Dep. Variable } \\
w_{i, t}(\text { Model 1-4); } \\
w_{i, t}+w_{j, t}(\text { Model 5-6) }\end{array}$ & $\begin{array}{c}\text { TEAM } \\
\text { Model } 1\end{array}$ & $\begin{array}{l}\text { INDIVIDUAL } \\
\text { Model } 2\end{array}$ & $\begin{array}{c}\text { MESSAGE } \\
\text { Model } 3\end{array}$ & $\begin{array}{c}\text { MESSAGE } \\
\text { Model } 4\end{array}$ & $\begin{array}{c}\text { MESSAGE } \\
\text { Model } 5\end{array}$ & $\begin{array}{c}\text { MESSAGE } \\
\text { Model } 6\end{array}$ \\
\hline$e_{i, t}$ & $\begin{array}{c}0.073 \\
(0.302)\end{array}$ & $\begin{array}{c}5.845^{* * * *} \\
(1.037)\end{array}$ & $\begin{array}{l}1.551 * * \\
(0.645)\end{array}$ & & & \\
\hline$e_{i, t}+e_{j, t}$ & $\begin{array}{c}2.778 * * * \\
(0.304)\end{array}$ & $\begin{array}{c}0.312 \\
(0.576)\end{array}$ & $\begin{array}{c}1.431 * * * \\
(0.386)\end{array}$ & $\begin{array}{l}-0.471 \\
(0.323)\end{array}$ & $\begin{array}{c}4.441 * * * \\
(0.458)\end{array}$ & $\begin{array}{c}4.070 * * * \\
(0.406)\end{array}$ \\
\hline$r_{i, t}$ & & & & $\begin{array}{c}5.004 * * * \\
(0.857)\end{array}$ & & \\
\hline Dishonesty & & & & $\begin{array}{c}-6.540 * * * \\
(2.001)\end{array}$ & $\begin{array}{l}-2.823 \\
(3.080)\end{array}$ & $\begin{array}{c}-11.422 * * * \\
(3.459)\end{array}$ \\
\hline $\begin{array}{c}\text { Dishonesty x } \\
r_{i, t}\end{array}$ & & & & $\begin{array}{c}-3.807 * * * \\
(0.944)\end{array}$ & & \\
\hline $\begin{array}{l}\text { Dishonesty x } \\
\quad\left(e_{i, t}+e_{j, t}\right)\end{array}$ & & & & $\begin{array}{c}2.371 * * * \\
(0.434)\end{array}$ & & $\begin{array}{l}1.051^{*} \\
(0.524)\end{array}$ \\
\hline Constant & $\begin{array}{l}-1.273 \\
(3.727) \\
\end{array}$ & $\begin{array}{l}-5.736 \\
(6.388) \\
\end{array}$ & $\begin{array}{c}0.869 \\
(2.115) \\
\end{array}$ & $\begin{array}{l}2.829 * * \\
(1.703)\end{array}$ & $\begin{array}{c}3.093 \\
(4.261)\end{array}$ & $\begin{array}{c}5.779 \\
(3.499)\end{array}$ \\
\hline$R^{2}$ overall & 0.680 & 0.586 & 0.691 & 0.690 & 0.728 & 0.720 \\
\hline Prob $>$ F & 0.000 & 0.000 & 0.000 & 0.000 & 0.000 & 0.000 \\
\hline $\mathrm{n}$ & 384 & 384 & 384 & 384 & 192 & 192 \\
\hline
\end{tabular}

Table 3: Fixed effects wage regressions. $e_{i, t}$ is the coefficient for individual effort, $e_{i, t}+e_{j, t}$ the coefficient for team effort, and $r_{i, t}$ is the coefficient for reported individual effort. "Dishonesty" is equal to one in all cases in which there is misreporting in the matching group, and zero otherwise. Robust standard errors adjusted for clusters in matching groups are presented in parentheses. Significance at the 10\%, 5\%, and 1\% level is denoted by *, **, and $* * *$, respectively. ${ }^{15}$

By contrast, principals' wage-setting in treatment INDIVIDUAL is significantly determined by agents' individual efforts. According to Model 2, every unit of individual effort increases individual wages by 5.845 . The small and insignificant coefficient $e_{i, t}+e_{j, t}$ indicates that, in this treatment, wage-setting is not influenced by the team effort per se.

As the regression analysis in Model 3 shows, principals in treatment MESSAGE systematically consider both types of information for their wage payment - individual effort and team effort. Principals conditioning their wages on reports and thereby rewarding individual effort can

\footnotetext{
${ }^{15}$ A Hausman test suggests the use of the fixed effects model over the random effects model. Moreover, note that censoring is not a problem in this setting - only few wages are set at the lower level (0) (TEAM: 31; INDIVIDUAL: 25; MESSAGE: 24) and no wages at the upper level (100).
} 
potentially explain the contrast to the wage-setting behavior in TEAM. Hence, agents' selfassessments indeed seem to affect principals' wage-setting.

Models 4-6 focus on treatment Message in more detail, in particular on the impact of (mis)reports. In Model 4, we analyze whether determinants of wage-setting differ in periods of truthful reporting from those in periods of misreporting. Therefore, we introduce a Dishonesty dummy that equals 1 in periods in which a principal is confronted with misreporting in the team. We also interact this dummy with the individual reports $r_{i, t}$, as well as the team effort $e_{i, t}+e_{j, t}$. The results show that, in periods with sincere reports, the principals take agents' self-assessments into account. The coefficient for reported effort $r_{i, t}(5.004)$ is positive and significant, while the small and insignificant coefficient of joint output $e_{i, t}+e_{j, t}$ $(-0.471)$ shows that team effort is largely disregarded. However, the principals change their behavior as soon as they are confronted with dishonest reports. Ceteris paribus, they remunerate the reported effort levels significantly less in periods with misreporting than in periods without misreporting (Dishonesty $\mathrm{x} r_{i, t}$ : -3.807). Instead, when confronted with insincere reports, the principals condition the wages on team output. The difference in principals' consideration of team effort between periods of truthful and untruthful reporting is substantial and significant (Dishonesty $\mathrm{x} e_{i, t}+e_{j, t}: 2.371$ ). Every unit of team effort is now rewarded with 1.9 units of additional wage $(-0.471+2.371)$. A Wald test for the combination of team effort $e_{i, t}+e_{j, t}$ and the interaction effect Dishonesty $\mathrm{x} e_{i, t}+e_{j, t}$ shows that these coefficients are jointly significant ( $\left.p r o b>\chi^{2}=.0000\right)$.

The results of Model 4, combined with the above findings on agents' reporting behavior, provide a potential explanation for the low efficiency in treatment MESSAGE. To see why, consider that the change in estimates caused by the shift from exclusively relying on agents' messages in periods of truthful reporting, to mainly considering team effort in periods of misreporting, implies monetary incentives for misreporting, which in turn constitutes a source of distrust among agents. In particular the low-performing agents have a strong incentive to over-report, as it provides them with the opportunity to free-ride on the other agent's effort. ${ }^{16}$

\footnotetext{
${ }^{16}$ To point out these lying incentives, it is useful to apply a sample calculation. Suppose the effort of agent $i$ is 4 and the effort of agent $j$ is 7 . Without misreporting, agent $i$ would - according to the estimates - receive a wage of $17.66\left(5.004 * 4\right.$ [Reported Effort $r_{i, t}$ ] $-0.471 * 11$ [Team Effort $\left.\left(e_{1, t}+e_{2, t}\right)\right]+2.829$ [Constant]). If he overreports by 1 (i.e., claims to have exerted an individual effort of 5), he would receive a higher wage of 23.174 (5.004*5 [Reported Effort $r_{i, t}$ ] $-0.471 * 11$ [Team Effort $\left.\left(e_{1, t}+e_{2, t}\right)\right]-6.540$ [Dishonesty] $-3.807 * 5$ [Dishonesty $x$ Reported Effort $\left.r_{i, t}\right]+2.371 * 11$ [Dishonesty x Team Effort $\left.\left(e_{1, t}+e_{2, t}\right)\right]+2.829$ [Constant]). Maximum overreporting (Reported Effort $r_{i, t}$ of 10) would even result in a wage of 29.159. Agent $j$ would receive a wage of
} 
Furthermore, the high-performing agents have an implicit incentive for misreporting as well, namely when they expect the co-worker to overstate his effort. In fact, if there is misreporting in the team anyway, it is beneficial for both agents to over-report to the maximum amount. ${ }^{17}$

Result 4: Principals tailor wages to self-assessments in periods of truthful reporting. In periods of misreporting, they largely disregard the reported effort levels and instead focus on actual team output. The observed wage payment patterns imply monetary incentives to over-report - not only for the low-performing agent in a team, but in general for those agents who expect the co-worker to misreport his effort level.

Ultimately, the previous regression analysis already suggests a rationale for the breakdown of gift exchange in treatment MESSAGE. On the one hand, it regularly pays off to lie for agents who exert lower effort than their co-agents. That way they can free-ride on the other's effort. On the other hand, high-performing agents who expect their co-worker to be dishonest should lie as well. This situation, with strong payoff incentives to overstate the own effort level, certainly has the potential to foster distrust among the agents in the team. One can imagine that none of the agents wants to "get the short end of the stick" for being honest.

A second reason for the failure of establishing successful gift-exchange relationships in treatment MESSAGE can be found in the general generosity of wage payments. In Model 4, we observe that misreporting can lead to lower wage payments, depending on the individual effort level and the sum of effort in the team. For example, the coefficient for Dishonesty (-6.540) is negative and significant. Models 5 and 6 further investigate whether principals "punish" the detection of dishonest behavior in the team, looking at a reduction in team wages $\left(w_{i}+w_{j}\right)$ rather than individual wages. Model 5 only includes team output and dishonesty as explanatory variables. Again, the coefficient for Dishonesty is large and negative (-2.823), but falls short of being significant in this specification. In Model 6, we additionally include the interaction between team output and dishonesty to reveal under which circumstances dishonesty is punished. The coefficient for Dishonesty is significantly negative (-11.422),

32.676 without any misreporting in the team. If he over-reports by 1 , he would receive a reduced wage of 26.765 .

${ }^{17}$ Consider the example from the previous footnote, assuming maximum over-reporting by agent $i$. In that case, agent $j$ would only receive a wage of 25.568 ( 7.108 less than without misreporting in the team). If we now assume that agent $j$ decides to misreport completely as well (reported effort of 10), he would receive 29.159. This is still less than in a period without any misreporting in the team, but more than with agent $j$ reporting truthfully and his co-agent $i$ misreporting. 
while the interaction Dishonesty $\mathrm{x}\left(e_{i}+e_{j}\right)$ is positive and significant (1.051). This suggests that dishonesty leads to strong wage reductions, but that this form of punishment via wage cuts is applied less intensely to high team efforts. ${ }^{18}$

Given that agents frequently misreport their efforts, the revealed wage-setting behavior directly translates into less generous wages in treatment MESSAGE. ${ }^{19}$ Looking at total wage payments, principals in MESSAGE pay the lowest wages (average of 20.15), followed by TEAM (33.24). Average wage payments are the highest in InDIVIDUAL (48.8). All differences are significant at the 5\% level (Wilcoxon rank sum test InDIVIDUAL vs. TEAM: $p=.0116$; Individual vs. MesSage: $p=.0002$; Team vs. Message: $p=.0382$ ).

Result 5: In particular when team effort is low, principals punish misreporting by paying lower wages. Overall, wage payments are least generous in treatment MESSAGE.

\section{Equity Principle}

We hypothesized that the perceived kindness of wage payments would be crucial for workers' motivation to exert high efforts. Parts of the perceived kindness also depend on the principals' ability and willingness to follow an equity principle. In our setting, the principal's ability to pay individual wages in accordance with the equity principle largely depends on the information about individual effort. Hence, we should observe principals' wage-setting to conflict with an equity norm least often in INDIVIDUAL and most often in treatment TEAM (remember that agents observe each other's efforts and wages and can infer equity norm violations from this information). Due to a limited, but non-negligible, amount of reliable additional information from the self-assessments, principals in MESSAGE should be able to follow the equity norm more often than in TEAM, but less often than in INDIVIDUAL. In fact, we observe exactly these patterns.

\footnotetext{
${ }^{18}$ Note that a principal always faces the problem that he does not know whom to punish and would certainly often hurt an innocent agent as well - which is likely to yield bigger drawbacks if team efforts are high. This may be one explanation for the observed diversity in punishment patterns. Still, all findings on wage-setting behavior point to general disturbances in trust between the principal and the team, as well as within the work team.

${ }^{19}$ Of course, the differences in absolute wage payments can to some extent be seen as the mirror image of differences in the effort provision, and thus efficiency.
} 


\begin{tabular}{|c|c|c|c|}
\hline $\begin{array}{c}\text { Dep. Variable } \\
\qquad e_{i, t}-e_{i, t-1} \\
\end{array}$ & Model 7 & Model 8 & Model 9 \\
\hline $\begin{array}{c}\text { Negative } \\
\text { viol }_{i, t-1}\end{array}$ & $\begin{array}{c}-2.268 * * * \\
(0.218)\end{array}$ & $\begin{array}{c}-1.989 * * * \\
(0.346)\end{array}$ & $\begin{array}{c}-1.284 * * \\
(0.523)\end{array}$ \\
\hline $\begin{array}{c}\text { Negative } \\
\text { viol }_{i, t-1} \times \text { MESSAGE }\end{array}$ & & $\begin{array}{l}-0.505 \\
(0.485)\end{array}$ & $\begin{array}{c}-2.073 * * \\
(1.027)\end{array}$ \\
\hline $\begin{array}{c}\text { Negative } \\
\text { viol }_{i, t-1} \mathrm{x} \text { INDIVIDUAL }\end{array}$ & & $\begin{array}{l}-0.369 \\
(0.663)\end{array}$ & $\begin{array}{c}1.833 \\
(2.611)\end{array}$ \\
\hline $\begin{array}{l}\text { Positive } \\
\text { viol }_{i, t-1}\end{array}$ & $\begin{array}{l}0.373^{*} \\
(0.215)\end{array}$ & $\begin{array}{c}0.579 \\
(0.393)\end{array}$ & $\begin{array}{c}0.504 \\
(0.374)\end{array}$ \\
\hline $\begin{array}{c}\text { Positive } \\
\text { viol }_{i, t-1} \times \text { MESSAGE }\end{array}$ & & $\begin{array}{l}-0.421 \\
(0.450)\end{array}$ & $\begin{array}{l}-0.370 \\
(0.431)\end{array}$ \\
\hline $\begin{array}{c}\text { Positive } \\
\text { viol }_{i, t-1} \mathrm{x} \text { INDIVIDUAL }\end{array}$ & & $\begin{array}{c}0.248 \\
(0.930)\end{array}$ & $\begin{array}{l}-0.167 \\
(0.979)\end{array}$ \\
\hline Constant & $\begin{array}{c}0.343 * * * \\
(0.073)\end{array}$ & $\begin{array}{c}0.320 * * * \\
(0.082)\end{array}$ & $\begin{array}{c}0.934 * * * \\
(0.154)\end{array}$ \\
\hline Additional Controls & None & None & $\begin{array}{c}\text { Period and } \\
\text { corresponding } \\
\text { interactions }\end{array}$ \\
\hline$R^{2}$ overall & 0.121 & 0.122 & 0.140 \\
\hline Prob $>F$ & 0.000 & 0.000 & 0.000 \\
\hline $\mathrm{n}$ & 1056 & 1056 & 1056 \\
\hline
\end{tabular}

Table 4: Fixed effects regressions on effort changes. Negative viol $i_{i, t-1}$ is equal to one if in $t-1$ an agent was negatively affected by an equity norm violation, Positive viol $i_{i, t-1}$ is equal to one if in t-1 an agent was positively affected by an equity norm violation, MESSAGE and INDIVIDUAL are treatment dummies, period controls are for changes over time (also contingent on treatment and negative violation). Robust standard errors adjusted for clusters in matching groups are presented in parentheses. Significance at the 10\%, 5\%, and $1 \%$ level is denoted by $*, * *$, and $* * *$, respectively.

Principals try to adhere to the equity principle whenever possible. ${ }^{20}$ In INDIVIDUAL, principals know the actual individual efforts and almost always pay wages in accordance with the equity principle. They violate the equity principle in less than $7 \%$ of all wage decisions. By contrast,

\footnotetext{
${ }^{20}$ In identifying violations of the equity principle at the team level, we consider the following cases as disadvantageous or negative (advantageous or positive) norm violations: agents either exert a higher (lower) individual effort than their co-agents and receive the same or a lower (higher) payoff, or they exert the same effort as their co-agent and receive a lower (higher) payoff. Accordingly, the norm is fulfilled when a lower (higher) effort is accompanied by a lower (higher) payoff, or when equal efforts lead to equal payoffs.
} 
principals in treatment TEAM are, by design, unable to condition their wage decisions on individual performances. Instead, they simply pay equal wages in most of the cases (84\%). However, whenever agents differ in their efforts, this goes along with inequitable payoffs. Consequently, principals in TEAM violate the equity principle much more often (in $67 \%$ of all cases) than those in INDIVIDUAL (Wilcoxon rank sum test for the aggregate number of violations per matching group - TEAM VS. INDIVIDUAL: $p<.0001)$. Looking at treatment MESSAGE, the additional information from the reports helps and the equity principle is violated less frequently than in TEAM: violations are reduced by $32 \%$ (Wilcoxon rank sum test - TEAM VS. MESSAGE: $p=.0237){ }^{21}$

Result 6: When the available information about individual efforts allows for it, principals frequently set wages that are line with the equity principle. Consequently, equity norm violations occur most often in treatment TEAM, less often in MESSAGE, and only rarely in INDIVIDUAL.

The regression analyses in Table 4 study the effect of disregarding the equity principle on agents' effort reactions in the subsequent period. They reveal that corresponding norm violations have a detrimental impact on effort. Model 7 captures the general pattern of effort reactions. Agents who are affected negatively by the norm violation significantly reduce effort (-2.268). Agents who are positively affected by the norm violation tend to increase effort (0.373), albeit not by the same amount by which agents suffering from norm violation reduce their effort. As every advantageous norm violation for one agent is accompanied by a disadvantageous norm violation for the co-agent, overall a negative impact is revealed. This general result is in line with previous evidence on behavior after equity norm violations (e.g., Abeler et al. 2010, Loewenstein et al. 1989, Mowday 1991).

Models 8 and 9 investigate whether the availability of private self-assessments in treatment MESSAgE induces different reactions to norm violations than in TEAM and INDIVIDUAL. This could be because workers in MESSAGE might (rightfully) expect their peers to frequently overstate their efforts, causing them to be more sensitive to relative wage payments, and to be more likely to perceive wage differences as unjustified and unkind. ${ }^{22}$ However, it turns out that the corresponding interaction effects between treatment MESSAGE and norm violation are

\footnotetext{
${ }^{21}$ For completeness: the number of equity norm violations is significantly lower in INDIVIDUAL than in MESSAGE (Wilcoxon rank sum test, $p<.0001$ ).

${ }^{22}$ In fact, $90 \%$ of all equity norm violations in MESSAGE are accompanied by misreporting in the team.
} 
only statistically significant if we additionally control for period effects, and only for negative norm violations. This can be seen by comparing the coefficients for negative/positive viol $_{i, t-1} \mathrm{x}$ MESSAGE between Models 8 and 9. ${ }^{23}$ We observe in Model 9 that agents' efforts react more strongly to disadvantageous (negative) norm violations in treatment MESSAGE (-2.073) than in the other two treatments. Moreover, the estimates for period controls (not reported in Table 4) additionally indicate that stronger effort reductions after norm violations in MESSAGE occur particularly in the first periods, and that these differences only vanish in later periods.

Result 7: Equity norm violations are detrimental for agents' effort provision in all treatments. However, in particular in early periods of the game, when confronted with a disadvantageous norm violation, agents in MESSAGE reduce efforts more strongly than those in treatments TEAM and INDIVIDUAL.

\section{Discussion}

Our experiment demonstrates that gift exchange in repeated interactions between principals and agents working in teams can be established, but that it is sensitive to the degree to which the principal is informed about the agents' individual efforts. In terms of efficiency, we see substantial differences across treatments. Full information about individual efforts is accompanied by the most efficient outcomes. If principals are not informed about agents' individual effort at all, agents' willingness to exert high efforts is reduced. Strikingly, adding the opportunity to increase information via truthful messages about individual effort levels hurts performance instead of helping it. Agents in the MESSAGE treatment perform substantially worse than those in the other treatments. This result is not due to reports being completely uninformative or the principals not relying on these reports at all. Reliable additional information due to the reporting is limited, but non-negligible. Whenever principals realize that both reports in the team are truthful, they systematically take the reports into account as an additional source of information for the wage-setting decisions. A positive consequence of truthful reports and principals relying on this additional source of information is the fact that the frequency of equity norm violations is lower in MESSAGE than in TEAM. However, such reporting possibilities can also lead to negative effects, which in our experiment offset and even exceed the positive aspects of reporting. It seems that

\footnotetext{
${ }^{23}$ Note that negative coefficients for the interaction effect indicate that agents i) reduce effort more strongly when negatively affected by a norm violation, and ii) decrease effort less strongly when positively affected.
} 
(mis)reporting spreads additional distrust in the principal-team setting as indicated by some patterns revealed in our analysis: less generous principals (in terms of wage payment); stronger negative effort reactions after equity norm violations; and, ultimately, significantly reduced effort contributions and therefore reduced efficiency.

Concerning potential policy implications, our results clearly show that it might be better to refrain from reports on individual performance, as long as the accompanied communication structures cannot effectively prevent the development of distrust among the concerned parties. However, the impact of the (lack of) information about individual effort and the effect of reporting on the agents' work morale most probably depends on a number of factors in the institutional setting that we did not test for in the present experiment: the firm-specific organizational structure, communication structure, and production technology. Results for three different settings were presented here; their robustness for other settings should be subject to future research. For instance, one could think of more complex reports and communication structures than the simple one-way communication, for example by using multi-task environments or adding more communication channels (e.g., two-way communication between agents in the team and a principal, or communication among agents). It might also be interesting to study the impact of team size on the effectiveness of reporting in such a setting; do more agents in the team reduce trust, because there are more potential sources of mistrust, or does team size increase trust since the marginal impact of each individual report vanishes the larger the team grows? Finally, it might be worthwhile to introduce more complex payment schemes, or to include alternative rewards for efforts (inkind benefits or symbolic awards), so that principals can use the information from the selfassessments to reward the agents along other dimensions. (Not only) these questions call for further experimental research in this fundamental field of interactions in organizations. 


\section{References}

Abeler, Johannes, Steffen Altmann, Sebastian Kube, and Matthias Wibral. 2010. "Gift Exchange and Workers' Fairness Concerns: When Equality Is Unfair." Journal of the European Economic Association, 8(6): 1299-1324.

Akerlof, George A. 1982. "Labor Contracts as Partial Gift-Exchange." Quarterly Journal of Economics, 97(4): 543-569.

Balliet, Daniel. 2010. "Communication and Cooperation in Social Dilemmas: A MetaAnalytic Review." Journal of Conflict Resolution 54(1): 39-57.

Bandiera, Oriana, Iwan Barankay, and Imran Rasul. 2013. “Team Incentives: Evidence from a Firm Level Experiment." Journal of the European Economic Association 11(5): 10791114.

Bartling, Björn, and Ferdinand A. von Siemens. 2011. "Wage Inequality and Team Production: An Experimental Analysis.” Journal of Economic Psychology, 32(1): 1-16.

Berger, Johannes, Christine Harbring, and Dirk Sliwka. 2013. "Performance Appraisals and the Impact of Forced Distribution-An Experimental Investigation." Management Science, 59(1): 54-68.

Brandts, Jordi, and David J. Cooper. 2007. "It's What You Say, not What You Pay: An Experimental Study of Manager-Employee Relationships in Overcoming Coordination Failure." Journal of the European Economic Association, 5(6): 1223-1268.

Burks, Stephen, Jeffrey Carpenter, and Lorenz Goette. 2009. "Performance Pay and Worker Cooperation: Evidence from an Artefactual Field Experiment." Journal of Economic Behavior and Organization, 70(3): 458-469.

Cabrales, Antonio, and Gary Charness. 2011. "Optimal Contracts with Team Production and Hidden Information: An Experiment." Journal of Economic Behavior and Organization, 77(2): 163-176. 
Campbell, Donald J., and Cynthia Lee. 1988. "Self-Appraisal in Performance Evaluation: Development versus Evaluation.” Academy of Management Review 13(2): 302-314.

Card, David, Alexandre Mas, Enrico Moretti, and Emmanuel Saez. 2012. "Inequality at Work: The Effect of Peer Salaries on Job Satisfaction" American Economic Review, 102(6): 2981-3003.

Charness, Gary, and Martin Dufwenberg. 2006. "Promises and Partnership." Econometrica, 74(6): 1579-1601.

Charness, Gary, and Martin Dufwenberg. 2011. "Participation." American Economic Review, 101(4): 1213-1237.

Charness, Gary, and Peter Kuhn. 2007. "Does Pay Inequality Affect Worker Effort? Experimental Evidence.” Journal of Labor Economics, 25(4): 693-723.

Charness, Gary, and Peter Kuhn. 2011. "Lab Labor: What Can Labor Economists Learn from the Lab?" In Orley Ashenfelter and David Card (eds.), Handbook of Labor Economics, Elsevier, Amsterdam, 4a: 229-330.

Clark, Andrew E., David Masclet, and Marie Claire Villeval. 2010. "Effort and Comparison Income: Experimental and Survey Evidence." Industrial and Labor Relations Review, 63: 407-426.

Crawford, Vincent. 1998. "A Survey of Experiments on Communication via Cheap Talk." Journal of Economic Theory, 78(2): 286-298.

Cohn, Alain, Ernst Fehr, Benedikt Herrmann, and Frédéric Schneider. 2012. "Social Comparison and Effort Provision: Evidence From a Field Experiment." Journal of the European Economic Association, forthcoming.

Cohn, Alain, Ernst Fehr, and Lorenz Götte. 2013. "Fair Wages and Effort Provision: Evidence from a Choice Experiment and a Field Experiment." Management Science, forthcoming. 
Cooper, David J., and John P. Lightle. 2013. "The Gift of Advice: Communication in a Bilateral Gift Exchange Game.” Experimental Economics, 16(4): 443-477.

Corgnet, Brice, and Roberto Hernán-González. 2013. "Don't Ask Me If You Will Not Listen: The Dilemma of Consultative Participation." Management Science, 60(3): 560-585.

\section{Dohmen, Thomas, Armin Falk, David Huffman, Uwe Sunde, Jürgen Schupp, and Gert}

G. Wagner. 2011. "Individual Risk Attitudes: Measurement, Determinants, and Behavioral Consequences." Journal of the European Economic Association, 9(3): 522-550.

Ederer, Florian, and Ernst Fehr. 2007. "Deception and Incentives: How Dishonesty Undermines Effort Provision.” IZA Discussion Paper 3200.

Falk, Armin. 2007. "Gift Exchange in the Field.” Econometrica, 75(5): 1501-1511.

Fehr, Ernst, Simon Gächter, and Georg Kirchsteiger. 1997. "Reciprocity as a Contract Enforcement Device: Experimental Evidence.” Econometrica, 65(4): 833-860.

Fehr, Ernst, Lorenz Goette, and Christian Zehnder. 2009. "A Behavioral Account of the Labor Market: The Role of Fairness Concerns.” Annual Review of Economics 1(1): 355-384.

Fehr, Ernst, Georg Kirchsteiger, and Arno Riedl. 1993. "Does Fairness Prevent Market Clearing? An Experimental Investigation." The Quarterly Journal of Economics, 108(2): 437-459.

Fischbacher, Urs. 2007. "z-Tree: Zurich Toolbox for Ready-made Economic Experiments." Experimental Economics, 10(2): 171-178.

Fischbacher, Urs, and Franziska Föllmi-Heusi. 2013. "Lies in Disguise. An Experimental Study on Cheating.” Journal of the European Economic Association, 11(3): 525-547.

Gächter, Simon, Daniele Nosenzo, and Martin Sefton. 2012. "The Impact of Social Comparisons on Reciprocity.” The Scandinavian Journal of Economics, 114(4) (2012): 13461367. 
Gächter, Simon, Daniele Nosenzo, and Martin Sefton. 2013. "Peer Effects in Pro-Social Behavior: Social Norms or Social Preferences?" Journal of the European Economic Association 11(3): 548-573.

Gächter, Simon, and Christian Thöni. 2010. "Social Comparison and Performance: Experimental Evidence on the Fair Wage-Effort Hypothesis." Journal of Economic Behavior \& Organization, 76(3): 531-543.

Gneezy, Uri. 2005. "Deception: The Role of Consequences." American Economic Review, 95(1): 384-394.

Gneezy, Uri, and John A. List. 2006. "Putting Behavioral Economics to Work: Testing for Gift Exchange in Labor Markets Using Field Experiments.” Econometrica, 74(5): 1365-1384.

Goerg, Sebastian J., and Sebastian Kube. 2012. "Goals (th)at Work: Goals, Monetary Incentives, and Workers' Performance." No. 2012/19. Preprints of the Max Planck Institute for Research on Collective Goods.

Goerg, Sebastian J., Sebastian Kube, and Ro‘i Zultan. 2010. "Treating Equals Unequally Incentives in Teams, Workers Motivation and Production Technology." Journal of Labor Economics, 28(4): 747-772.

Gose, Karina, and Abdolkarim Sadrieh. 2014. "Strike, Coordination, and Dismissal in Uniform Wage Settings.” European Economic Review, 70: 145-158.

Greiner, Ben. 2004. “An Online Recruitment System for Economic Experiments." Forschung und wissenschaftliches Rechnen, 63: 79-93.

Greiner, Ben, Axel Ockenfels, and Peter Werner. 2011. "Wage Transparency and Performance: A Real-Effort Experiment.” Economics Letters 111(3): 236-238.

Hennig-Schmidt, Heike, Abdolkarim Sadrieh, and Bettina Rockenbach. 2010. "In Search of Workers' Real Effort Reciprocity-A Field and a Laboratory Experiment.” Journal of the European Economic Association, 8(4): 817-837. 
Holmström, Bengt. 1982. "Moral Hazard in Teams.” Bell Journal of Economics, 13(2): 324340.

Kosfeld, Michael, and Susanne Neckermann, 2011. "Getting More Work for Nothing? Symbolic Awards and Worker Performance.” American Economic Journal: Microeconomics, 3(3): 86-99.

Kube, Sebastian, Michel André Maréchal, and Clemens Puppe. 2012. "The Currency of Reciprocity - Gift-Exchange in the Workplace.” American Economic Review, 102(4): 16441662.

Kube, Sebastian, Michel André Maréchal, and Clemens Puppe. 2013. "Do Wage Cuts Damage Work Morale? Evidence from a Natural Field Experiment.” Journal of the European Economic Association, 11(4): 853-870.

Lazear, Edward P. 2000. "Performance, Pay and Productivity." American Economic Review, 90 (5), 1346-1361.

Levy, Paul E., and Jane R. Williams. 2004. "The Social Context of Performance Appraisal: A Review and Framework for the Future.” Journal of Management, 30(6): 881-905.

Loewenstein, George, Leigh Thompson, and Max Bazerman. 1989. "Social Utility and Decision Making in Interpersonal Contexts." Journal of Personality and Social Psychology, 57(3): 426-441.

Lount, Robert and Steffanie Wilk. 2014. "Working Harder or Hardly Working? Posting Performance Eliminates Social Loafing and Promotes Social Laboring in Workgroups." Management Science, 60(5): 1098-1106.

Mayer, Roger C., and James H. Davis. 1999. "The Effect of the Performance Appraisal System on Trust for Management: A Field Quasi-Experiment." Journal of Applied Psychology, 84(1): 123-136.

Maximiano, Sandra, Randolph Sloof, and Joep Sonnemans. 2007. "Gift Exchange in a Multi-Worker Firm.” The Economic Journal, 117(522):1025-1050. 
Mohnen, Alwine, and Kathrin Pokorny. 2006. "Is Honesty the Best Policy? An Experimental Study on the Honesty of Feedback in Employer-Employee Relationships." University of Cologne Discussion Paper.

Mowday, Richard T. 1991. "Equity Theory Predictions of Behavior in Organizations." In Motivation and Work Behavior, Richard M. Steers and Lyman W. Porter (eds.), 111-131. New York: McGraw-Hill.

Nosenzo, Daniele. 2013. "Pay Secrecy and Effort Provision.” Economic Inquiry, 51(3): 17791794.

Ockenfels, Axel, Dirk Sliwka, and Peter Werner. Forthcoming. "Bonus Payments and Reference Point Violations." Management Science, forthcoming.

Prendergast, Canice. 1999. "The Provision of Incentives in Firms." Journal of Economic Literature, 37 (1): 7-63.

Prendergast, Canice, and Robert Topel. 1993. "Discretion and Bias in Performance Evaluation." European Economic Review, 37(2): 355-365.

Rosaz, Julie. 2012. “Biased Information and Effort.” Economic Inquiry, 50(2):484-501.

Sanchez-Pages, Santiago, and Marc Vorsatz. 2007. "An Experimental Study of TruthTelling in a Sender-Receiver Game." Games and Economic Behavior, 61(1): 86-112.

Sebald, Alexander, and Markus Walzl. 2014. "Subjective Performance Evaluations and Reciprocity in Principal-Agent Relations." The Scandinavian Journal of Economics, 116(2): $570-590$

Winter, Eyal. 2004. "Incentives and Discrimination." American Economic Review, 94(3): 764-73. 